\title{
Live imaging analysis of human gastric epithelial spheroids reveals spontaneous rupture, rotation and fusion events
}

\section{Authors: T. Andrew Sebrell, Rachel Bruns, Royce A. Wilkinson, Blake Wiedenheft, Paul J. Taylor, Brian A. Perrino, Linda C. Samuelson, James N. Wilking, and Diane Bimczok.}

The final publication is available at Springer via https://doi.org/10.1007/s00441-017-2726-5

Sebrell TA, B Sidar, R Bruns, RA Wilkinson, B Wiedenheft, PJ Taylor, BA Perrino, LC Samuelson, JN Wilking, D Bimczok, "Live imaging analysis of human gastric epithelial spheroids reveals spontaneous rupture, rotation and fusion events," Cell and Tissue Research. February 2018;371(2):293-307. doi: 10.1007/s00441-017-2726-5. 


\title{
Live imaging analysis of human gastric epithelial spheroids reveals spontaneous rupture, rotation and fusion events
}

T. Andrew Sebrell, Barkan Sidar, Rachel Bruns, Royce A. Wilkinson, Blake Wiedenheft, Paul J. Taylor, Brian A. Perrino, Linda C. Samuelson, James N. Wilking, Diane Bimczok

\begin{abstract}
Three-dimensional cultures of primary epithelial cells including organoids, enteroids and epithelial spheroids have become increasingly popular for studies of gastrointesti-nal development, mucosal immunology and epithelial infec-tion. However, little is known about the behavior of these complex cultures in their threedimensional culture matrix. Therefore, we performed extended time-lapse imaging analy-sis (up to 4 days) of human gastric epithelial spheroids gener-ated from adult tissue samples in order to visualize the dynam-ics of the spheroids in detail. Human gastric epithelial spher-oids cultured in our laboratory grew to an average diameter of $443.9 \pm 34.6 \mu \mathrm{m}$ after 12 days, with the largest spheroids reaching diameters of $>1000 \mu \mathrm{m}$. Live imaging analysis re-vealed that spheroid growth was associated with cyclic rupture of the epithelial shell at a frequency of $0.32 \pm 0.1$ day, which led to the release of luminal contents. Spheroid rupture usually resulted in an initial collapse, followed by spontaneous re-formation of the spheres. Moreover, spheroids frequently rotated around their axes within the Matrigel matrix, possibly propelled by basolateral pseudopodia-like formations of the epithelial cells. Interestingly, adjacent spheroids occasionally underwent luminal fusion, as visualized by injection of indi-vidual spheroids with FITCâ€“Dextran ( $4 \mathrm{kDa})$. In summary, our analysis revealed unexpected dynamics in human gastric spheroids that challenge our current view of cultured epithelia as static entities and that may need to be considered when performing spheroid infection experiments.
\end{abstract}

In recent years, epithelial organoids have become increasingly popular as a new and powerful tool to study gastrointestinal development and disease (Dedhia et al. 2016; Hynds and Giangreco 2013; Leushacke and Barker 2014). Since the ini-tial description of epithelial organoids derived from murine intestine (Ootani et al. 2009; Sato et al.2009), organoid cul-ture systems have been adapted to multiple epithelial organ systems and species (Powell and Behnke 2017; Sato and Clevers 2015). For the first time, primary gastrointestinal ep-ithelial cells from various species can now be propagated for extended periods of time by culturing the cells in a three-dimensional collagen matrix and by supplementing Wnt3a, noggin and R-spondin to support maintenance of the stem cell compartment. Importantly, the utilization of adult stem cells enables the generation of primary epithelial cell lines from patient tissues with the potential of performing translational studies and patient-specific analyses (Dekkers et al. 2013; VanDussen et al. 2015). The availability of established proto-cols for primary epithelial cell cultures has led to exponential 
growth in publications using these methods over the last 5 years, with the number of "organoid" publications per year increasing from $<10$ in 2007 to $\geq 450$ in 2016 . Thus, various forms of organoid cultures are starting to replace more traditional epithelial culture methods that involve the use of transformed cell lines derived from gastrointestinal tumors.

However, little is known about the behavior of these complex living spheres in their three-dimensional matrix, beyond diametrical expansion due to cell proliferation. Several publications on gastrointestinal organoids or spheroids include video supplements showing growth over time (Mahe et al. 2013; Schlaermann et al. 2016; Schumacher et al. 2015; Schwank et al. 2013). Some of these videos challenge our concept of epithelial organoids as static entities that undergo diametrical growth, though the dynamic behaviors observed were not evaluated in detail.

In our study, we established primary gastric epithelial cell lines from 13 healthy human adults. These lines were maintained as spheroids following the protocol published by Miyoshi and Stappenbeck (2013), which has been used by multiple groups to culture organoids from intestinal (Bradford et al. 2017; Howitt et al. 2016; Powell and Behnke 2017; Riehl et al. 2015) and gastric sites (Demitrack et al. 2017; den Hartog et al. 2016; Gifford et al. 2017; VanDussen et al. 2015). With these cultures, we performed live imaging analysis for up to 4 days. Under the culture conditions used, rupture events occurred cyclically in the majority of the cultures imaged and were associated with the release of luminal material and subsequent healing of the majority of spheroids. In addition, we also observed spheroids that rotated in the Matrigel and spheroids that fused with other spheroids. These observations indicate that human gastric spheroid cultures are surprisingly dynamic, at least under the specific culture conditions used here. Notably, the epithelial barrier function of the spheroids may temporarily be compromised because of relatively common spontaneous rupture events that are not visible using routine monitoring techniques.

\section{Materials and methods}

\section{Human gastric epithelial spheroid culture}

Thirteen gastric tissue specimens from sleeve gastrectomy surgeries were obtained with Institutional Review Board (IRB) approval by the National Disease Research Interchange (NDRI; Philadelphia, PA, USA) or by Dr. Kent Sasse (Sasse Surgical Associates, Reno, NV, USA). Donor characteristics are listed in Table 1. Information on pathological alteration of the tissues was provided by the NDRI. Gastric glands were isolated as described previously (Bimczok 2013, 2014). Briefly, we dissected the gastric mucosa off the muscle layer and cut the mucosa into $<1-\mathrm{mm}$ pieces, which were placed into RPMI-1640 medium supplemented with $0.5 \mathrm{U} / \mathrm{mL}$ collagenase type IV, $0.2 \mathrm{mg} / \mathrm{mL}$ DNAse (Sigma-Aldrich, St. Louis, MO, USA), 0.3\% BSA, $250 \mu \mathrm{g} / \mathrm{mL}$ amphotericin B (Fisher Scientific, Fair Lawn, $\mathrm{NJ}$, USA), $100 \mathrm{U} / \mathrm{mL}$ penicillin/streptomycin, $2 \mathrm{mM}$ L-glutamine, $1 \mathrm{mM}$ HEPES (GE Healthcare Life Sciences, Logan UT, USA) and $50 \mu \mathrm{g} / \mathrm{mL}$ Gentamycin (IBI Scientific, Peosta, IL, USA). The tissue was incubated at $200 \mathrm{rpm}$ in a $37^{\circ} \mathrm{C}$ water bath for $1 \mathrm{~h}$. The tube was then vortexed for $30 \mathrm{~s}$ to release glands from the tissue. To establish gastric spheroid cultures, the glands and remaining tissue pieces were centrifuged at $200 \mathrm{~g}$ at $4{ }^{\circ} \mathrm{C}$ for $5 \mathrm{~min}$. The pellet was resuspended in $30 \mathrm{~mL}$ ice-cold DPBS (Hyclone GE Healthcare Life Sciences) and vortexed again for $30 \mathrm{~s}$. Tissue pieces were allowed to settle to the bottom of the tube and gastric glands in the supernatant were transferred to a new $50-\mathrm{mL}$ tube, pelleted and transferred to Matrigel (Corning, Bedford, MA, USA). Glands suspended in Matrigel were pipetted into a prewarmed 24-well plate. Gastric spheroid cultures were maintained following the protocol of Miyoshi and Stappenbeck (2013), with minor modifications as described by Gifford et al. (2017). After polymerization, Matrigel was overlaid with $500 \mu \mathrm{L}$ of L-WRN medium composed of Advanced DMEM/F12 (Gibco by Life Technologies, Grand Island, NY, USA) supplemented with $10 \mathrm{mM}$ HEPES, $1 \%$ Pen/ Strep, 50\% L-WRN conditioned medium, $10 \mu \mathrm{M}$ ROCKinhibitor Y-27632 (Tocris Biosciences, Bristol, UK), Amphotericin B, Gentamycin, L-Glutamine, $10 \mu \mathrm{M}$ TGF- $\beta$ inhibitor SB-431542 (Tocris), 10\% FBS (Rocky Mountain Bio, Missoula, MT, USA) and $50 \%$ of cell culture supernatant from L-WRN cells, which constitutively secrete murine Wnt3a, noggin and R-spondin 3 (Miyoshi et al. 2012). LWRN cells were kindly provided by Dr. T. Stappenbeck, Washington University, St. Louis, USA. The final concentration of Wnt $3 \mathrm{a}$ in the culture media was $6.2 \pm 0.2 \mu \mathrm{g} / \mathrm{mL}$ as determined by testing 3 individual supernatants from L-WRN cells with the TopFlash assay (van de Wetering et al. 1991), using the Firefly Luciferase Assay Kit 2.0 (Biotium, Fremont, CA, USA) and recombinant murine Wnt3a (Peprotech, Rocky Hill, NJ, USA) as a standard. Formed spheroids were maintained in a $37{ }^{\circ} \mathrm{C}, 5 \% \mathrm{CO}_{2}$ incubator, with fresh medium added every $2-3$ days and were passaged by trypsinization and re-plating at 1:4 every 5-7 days. The conditions used in this study allowed the continuous culture of human gastric spheroids for at least 50 passages (approximately 11 months), without apparent changes in growth, morphology or viability.

\section{Immunohistochemistry and immunofluorescence analysis}

For paraffin-embedded sections, Matrigel plugs containing spheroids were fixed in 10\% neutral buffered formalin (Richard Allen Scientific, Kalamazoo, MI, USA). Paraffin- 
Table 1 Organoid lines and donor characteristics used in this study

\begin{tabular}{lllll}
\hline Organoid line & Tissue & Donor (age/sex) & Pathology & Experiments \\
\hline hu001 & Gastric body & $45 / \mathrm{F}$ & Polypoid fundic nodules & Imaging, FACS \\
hu002 & Gastric body & $49 / \mathrm{F}$ & Moderate gastritis & Imaging, FACS \\
hu003 & Gastric body & $45 / \mathrm{F}$ & Mild gastritis & FACS \\
hu004 & Gastric body & $52 / \mathrm{F}$ & Mild chronic inflammation & Imaging, FACS \\
hu005 & Gastric body & $38 / \mathrm{F}$ & No alterations observed & FACS \\
hu006 & Gastric antrum & $42 / \mathrm{F}$ & Not available & Imaging, FACS \\
hu007 & Gastric body & $26 / \mathrm{F}$ & Not available & FACS \\
hu008 & Gastric body & $35 / \mathrm{F}$ & No alterations observed & Imaging, FACS \\
hu009 & Gastric body & $31 / \mathrm{F}$ & No alterations observed & FACS \\
hu010 & Gastric body & $43 / \mathrm{F}$ & Mild gastritis & FACS \\
hu011 & Gastric body & $52 / \mathrm{M}$ & No alterations observed & qRT-PCR \\
hu013 & Gastric body & $57 / \mathrm{M}$ & Not available & qRT-PCR \\
hu014 & Gastric body & $57 / \mathrm{M}$ & No alterations observed & qRT-PCR \\
\hline
\end{tabular}

embedded sections were prepared on a Sakura Tissue-Tek VIP1000 tissue processor and embedding center and sectioned at $5 \mu \mathrm{m}$ on a Leica 2035 rotary microtome. Sections were stained with hematoxlin-eosin (HE) reagent (Richard Allen Scientific). For whole-mount staining, gastric epithelial spheroids grown on 8-well chamber slides were fixed for 30 min at $4{ }^{\circ} \mathrm{C}$ in Cytofix (BD Biosciences, San Diego, CA, USA). Samples were blocked in PBS containing $10 \%$ FBS (Rocky Mountain Bio), 0.2\% Triton X-100, 0.1\% BSA and $0.05 \%$ Tween-20 (Fisher Scientific) and were incubated with primary antibody overnight at $4{ }^{\circ} \mathrm{C}$. The following primary antibodies were used: mouse anti-human cytokeratin, clone CAM5.2 (BD Biosciences, San Jose, CA, USA; recognizes Moll's cytokeratin peptide \#8 and \#7) and mouse anti-human E-Cadherin, clone 67A4 (BioLegend, San Diego, CA, USA). Wells were washed with DPBS and isotype-specific Alexa488-labeled secondary antibody (SouthernBiotech, Birmingham, AL, USA) was added for $2 \mathrm{~h}$ at room temperature. After a final wash step, samples were covered with ProLong Gold with DAPI (Fisher Scientific).

\section{Quantitative RT-PCR}

Total RNA was isolated from epithelial spheroids and human gastric tissue samples using the Direct-zol RNA MiniPrep Kit (ZymoResearch, Irvine, CA, USA). Complementary DNA was generated using reverse transcription performed from $1 \mu \mathrm{g}$ RNA using the iScript cDNA Synthesis Kit (Bio-Rad Laboratories, Hercules, CA, USA). qPCR was performed using iTaq Universal SYBR Green Supermix (Bio-Rad) on a Roche LightCyler96 (Roche, Basel, Switzerland). PCR primers sequences used are listed in Suppl. Table 1. PCR data were analyzed using the $2^{-\Delta \Delta \mathbf{C T}}$ method, with gastric spheroid gene expression normalized to GAPDH and gene expression in human gastric tissue.

\section{Growth measurements and counting}

To determine spheroid size, cultures were imaged by phase contrast microscopy and spheroid diameters were measured on composite images of entire culture wells. To obtain cell counts, spheroid cultures were incubated with $0.25 \%$ Trypsin EDTA solution (EMD Millipore, Billerica, MA, USA) at $37{ }^{\circ} \mathrm{C}$ for $5-7 \mathrm{~min}$ and mixed with a pipet tip until a single cell suspension was obtained. Cells were then counted on a hemocytometer or on a flow cytometer using reference cells (Pechhold et al. 1994).

\section{Generation of EGFP- and mCherry-expressing spheroids by lentiviral transduction}

To produce lentiviral particles, HEK293 cells were plated at $40 \%$ confluency in DMEM/10\% fetal calf serum/penicillin/ streptomycin the day before transfection. One hour before transfection, the media was replaced with pre-warmed OptiMEM (Gibco, Grand Island, NY, USA). Cells were cotransfected with pCMV-VSV-G (a gift from Bob Weinberg; Addgene plasmid \# 8454; Stewart et al. 2003), psPAX2 (a gift from Didier Trono; Addgene plasmid \# 12260) and either pLJM1-EGFP (a gift from David Sabatini; Addgene plasmid \# 19319; Sancak et al. 2008) or pLV-mCherry (a gift from Pantelis Tsoulfas; Addgene plasmid \# 36084) using Lipofectamine 3000 (ThermoFisher) according to the manufacturer's instructions. Six hours after transfection, the OptiMEM was removed and replaced with DMEM/10\% fetal calf serum $/ 1 \%$ BSA. The supernatant containing the lentivirus was harvested $48 \mathrm{~h}$ and $60 \mathrm{~h}$ post-transfection. The combined (48 $\mathrm{h}$ and $60 \mathrm{~h}$ ) samples were centrifuged for $10 \mathrm{~min}$ at $1000 \mathrm{~g}$ at $4{ }^{\circ} \mathrm{C}$, filtered through a low-protein binding $0.45-\mu \mathrm{m}$ filter and concentrated by ultracentrifugation $\left(80,000 \mathrm{~g}\right.$ at $4{ }^{\circ} \mathrm{C}$ for $2 \mathrm{~h}$ ). The virus was resuspended by overnight incubation at 
$4{ }^{\circ} \mathrm{C}$ in DMEM $/ 10 \% \mathrm{FCS} / 1 \% \mathrm{BSA}$, aliquoted and stored at $-80^{\circ} \mathrm{C}$.

To perform lentiviral transduction of gastric spheroids, the spheroids were harvested and trypsinized to obtain a single cell suspension. Cells were suspended in spheroid L-WRN media prepared with $10 \mu \mathrm{M}$ ROCK Inhibitor Y-27632 (Tocris Biosciences) and hexadimethrine bromide (SigmaAldrich). Cells were incubated with $30 \mu \mathrm{L}$ of lentivirus in $250 \mu \mathrm{L} \mathrm{L}-W R N$ media and incubated at $37{ }^{\circ} \mathrm{C}$ in $5 \% \mathrm{CO}_{2}$. After $6 \mathrm{~h}$, suspensions were transferred to Eppendorf tubes and centrifuged at $500 \mathrm{~g}$ for $5 \mathrm{~min}$. Epithelial cells were transferred to Matrigel and plated into a warmed 24-well plate for further culture and were maintained in the presence of puromycin (Sigma) for EGFP. Spheroids with high EGFP or mCherry expression were derived from FACS-purified single-cell suspensions.

\section{Microinjection of gastric spheroids with FITC-Dextran}

A Fisher stereomicroscope fitted with a Genesearch Embryo Cradle (Genesearch, Bozeman, MT, USA) and a $2 \mu \mathrm{L}$ syringe (Hamilton, Reno, NV, USA) was used for microinjection. Injection needles with beveled tips were pulled from glass capillaries to a size of 21-23 $\mu \mathrm{m}$. For the injection, 10-day plated spheroids in $35 \mathrm{~mm}$ MatTek dishes were injected with $0.2 \mu \mathrm{L}$ of $25 \mu \mathrm{M}$ FITC-Dextran $4 \mathrm{kDa}$ (Sigma-Aldrich, St. Louis, MO, USA). Spheroids were left in the Matrigel matrix for injection.

\section{Microscopic analysis}

Epiflourescence and phase contrast images were acquired using a Life Technologies EVOS FL Auto system equipped with an onstage incubator. Live confocal imaging analysis was performed on an inverted Leica SP5 Confocal Scanning Laser Microscope with 405-, 488-, 561- and 633-nm laser excitation lines and a heated stage with an environmental control chamber. Fluorescence, phase contrast and backscattered light images were collected at 10-min intervals over 17-112 h using a $\times 10$ objective. Backscattered laser light images were obtained by adjusting the wavelength range of the imaging detector to capture the excitation laser wavelength. This technique allows the visualization of interfaces between materials of different densities.

For transmission electron microscopy analysis (Brumfield et al. 2009), epithelial spheroid cultures were fixed overnight with $3 \%$ glutaraldehyde in $0.05 \mathrm{M}$ potassium sodium phosphate buffer, $\mathrm{pH} 7.2$, followed by postfixation in $2 \%$ osmium tetroxide for $4 \mathrm{~h}$. Samples were dehydrated using an ethanol series (50-100\%) and propylene oxide. After dehydration, epithelial spheroids were gradually infiltrated with Spurr's resin and baked overnight at $70{ }^{\circ} \mathrm{C}$. Then, 60 - to 90 -nm ultrathin sections were cut with a Diatome diamond knife on a
Reichert OM-U2 ultramicrotome, floated onto 300-mesh copper grids and stained with uranyl acetate and Reynold's lead citrate. All sections were viewed with a LEO 912AB TEM and photographed with a Proscan $2048 \times 2048$-pixel chargecoupled-device camera.

\section{Results}

\section{Phenotypic analysis of human gastric epithelial spheroids}

To confirm the identity and differentiation stage of our gastric epithelial spheroid lines maintained using the protocol of Miyoshi and Stappenbeck (2013), we first performed phenotypic analyses using light microscopy, qRT-PCR and transmission electron microscopy (TEM). As anticipated, the epithelial cells formed spheroids with columnar to cuboidal epithelium and expressed epithelial cytokeratin and E-cadherin (Fig. 1a-c). Quantitative RT-PCR analysis of the gastric spheroids confirmed expression of genes specific for all five major gastric epithelial cell subsets, i.e., parietal cells (ATP4B), chief cells (pepsinogen C, $P G C$ ), surface mucus cells (MUC5ac), mucus neck cells (MUC6) and enteroendocrine cells (chromogranin A, CHGA; Fig. 1d). Notably, gene expression for the enteroendocrine marker CHGA was very low. Moreover, gene expression levels of all five genes analyzed were decreased compared to the levels detected in the gastric biopsy specimens that were used as positive controls for PCR normalization.

Ultrastructural analysis by TEM revealed that the gastric spheroids contained several morphologically distinct cell types (Fig. 2). The predominant cell type was a secretorytype cell with large electron-dense vesicles in the apical portion of the cell (Fig. 2a, a'), comparable to a mucus pit cell (Corpron 1966; Zeitoun and Lambling 1967). Cells with electron-lucent vesicles near their luminal surface were also present (Fig. 2a, a"), similar to mucus neck cells. Some cells had large amounts of rough ER and mitochondria, consistent with active protein synthesis as typically found in chief cells (Fig. 2b) (Zeitoun and Lambling 1967). Moreover, we also detected cells with large intracellular canaliculi with projecting microvilli, similar to those described for parietal cells (Fig. 2c) (Rohrer et al. 1965). We did not detect any cells with basal vesicles typical for enteroendocrine cells. Consistent with the general morphology of the gastrointestinal epithelium, spheroid cells had basal nuclei, short apical microvilli (Fig. 2d, d') and distinct apical junctional complexes (Fig. 2e). We also observed extensive formation of interdigitating lateral processes (Fig. 2d, f), as shown by Necchi et al. (2009) for human gastric mucosa. Overall, gastric spheroids show typical features of the human gastric epithelium but do not appear to be fully differentiated. 

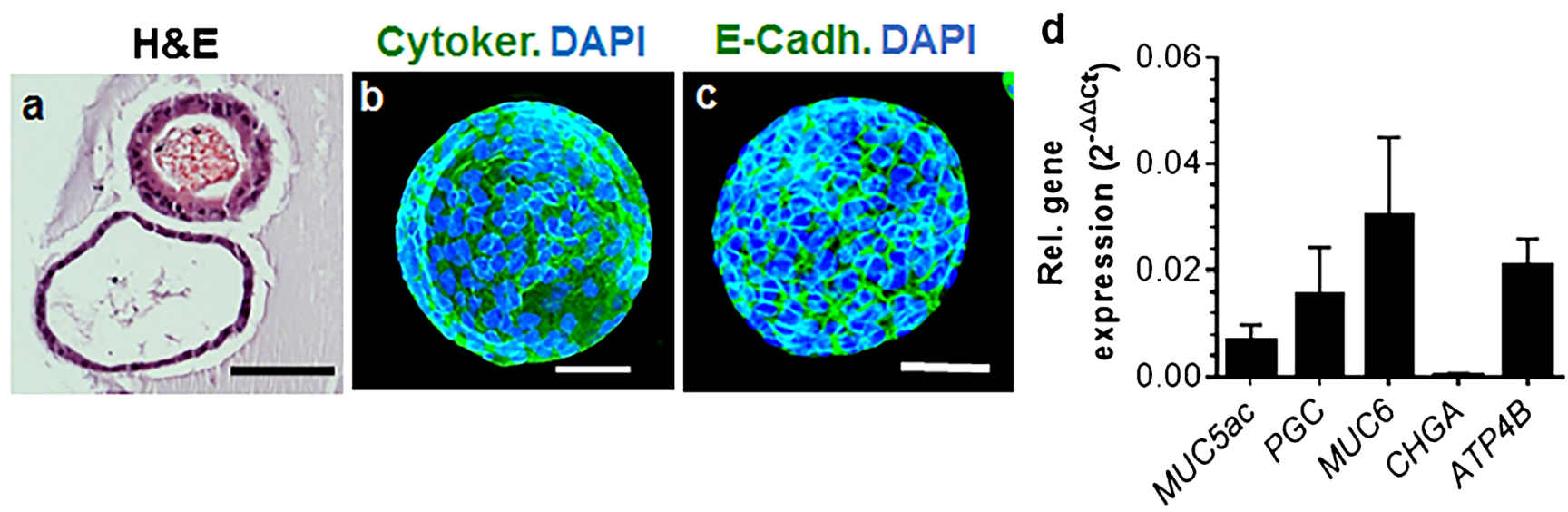

Fig. 1 Microscopic analysis and gene expression analysis of human gastric epithelial spheroids. a Spheroids were fixed, paraffin-embedded and sections stained with hematoxylin-eosin. Bar $50 \mu \mathrm{m}$. b, c E-Cadherin (FITC) and cytokeratin (FITC) whole-mount immunofluorescence staining of human gastric spheroids; nuclei were labeled with DAPI. Bar $50 \mu \mathrm{m}$. d Quantitative RT-PCR analysis of gastric spheroids $(n=3$; hu011, hu013 and hu014). Samples were analyzed for expression of

MUC5A (mucous neck cells), PGC (pepsinogen C; chief cells), MUC6 (surface mucus cells), CHGA (chromogranin A, enteroendocrine cells) and $A T P 4 B$ (Potassium-transporting ATPase subunit beta, parietal cells). Data were analyzed by the $2^{-\triangle \Delta \mathrm{CT}}$ method, with $G A P D H$ used as a housekeeping gene and cDNA from human gastric tissue (geometric mean of $n=3$ ) used for normalization
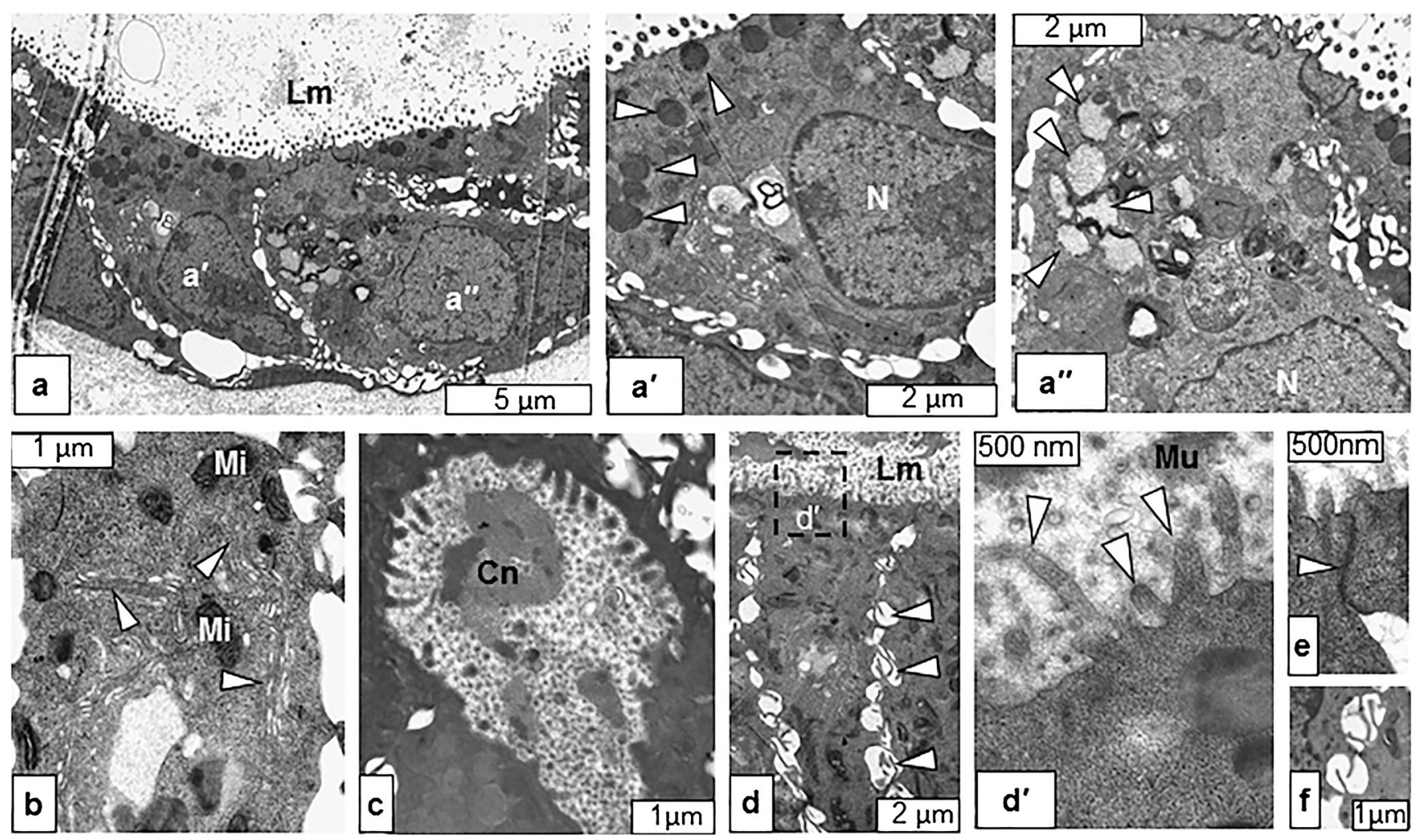

Fig. 2 Transmission electron microscopy of human gastric epithelial spheroids. a Cross-section of a gastric spheroid shows a simple cuboidal to columnar microvillated epithelium with vacuolated secretory cells and basal nuclei. $L m$ lumen; bar $5 \mu \mathrm{m}$. a' Epithelial cell from (a) with large, electron-dense vacuoles (arrowheads). $N$ nucleus; bar $2 \mu \mathrm{m}$. a" Epithelial cell from (a) with large, electron-lucent vacuoles (arrowheads). $N$ nucleus; bar $2 \mu \mathrm{m}$. b Epithelial cell with copious amounts of rough endoplasmic reticulum (arrowheads) and

multiple large mitochondria $(M i)$; bar $1 \mu \mathrm{m}$. c Large microvillated intracellular canaliculus $(\mathrm{Cn})$ in a gastric epithelial cell. Bar $1 \mu \mathrm{m}$. d Columnar epithelial cells with luminal microvilli and lateral interdigitating intercellular leaflets (arrowheads)b bar $2 \mu \mathrm{m}$. d' Enlarged image from (d, dashed box) shows luminal microvilli (arrowheads) and mucus (Mu); bar $500 \mathrm{~nm}$. e Luminal-junctional complex (arrowhead) between two epithelial cells; bar $500 \mathrm{~nm}$. (f) Lateral interdigitating intercellular leaflets; bar $1 \mu \mathrm{m}$ 


\section{Growth dynamics of human gastric epithelial spheroids}

Next, we analyzed spheroid growth dynamics, size distribution and cellularity of the spheroids (Fig. 3). Spheroids expanded in size over a period of around 10 days and then plateaued, with a median diameter of $398 \mu \mathrm{m}$ (average $443.9 \pm 34.6 \mu \mathrm{m}$ ) after 12 days of culture (Fig. 3a-a'"', b). Spheroids within one culture well varied significantly in size (Fig. 3c). To determine the size distribution of gastric spheroids within a culture, spheroids from 4 different lines were grown until the largest ones reached a size of $>600 \mu \mathrm{m}$. Cultures were then imaged and spheroid diameters measured on composite digital images of culture wells (Fig. 3d). Size distribution was remarkably consistent between individual spheroid lines and followed a right-skewed bell curve, with $73 \pm 8 \%$ of spheroids only reaching diameters of $\leq 300 \mu \mathrm{m}$. A small subset of spheroids $(0.4 \pm 0.4 \%)$ reached diameters of $\geq 800 \mu \mathrm{m}$ after $7-10$ days of culture.

Using composite images of entire culture wells, digital image measurements and manual cell counting of single cell suspensions derived from the spheroids, we determined the average relationship between spheroid size and cell numbers in our cultures (Fig. 3e), with $n$ being equivalent to the numbers of cells that can be recovered from a spheroid of a defined radius (in $\mu \mathrm{m}$ ):

$n=(0.00395 \pm 0.0007) \frac{1}{\mu m} 4 \pi r$

These cell counts correspond to a radius of $20 \mu \mathrm{m}$ per single epithelial cell. Similar results were obtained using FACSbased cell counting with reference cells (Pechhold et al. 1994). The number of cells per spheroid can be used to assess the recovery of DNA, RNA and protein from cultures with organoids of certain sizes and to calculate the multiplicity of infection for pathogen microinjection experiments.

\section{Spontaneous rupture and healing events of human gastric organoids}

Based on published and anecdotal reports of organoid rupture events (Mahe et al. 2013; Schlaermann et al. 2016; Schwank et al. 2013), we performed live imaging analysis of six distinct human gastric spheroid lines, with 9-83 spheroids per line imaged over 17-112 h. As shown in Fig. 4a-a'"' and Suppl. Movie 1, spheroids frequently oscillated in diameter, consistent with rupture and healing processes. We observed an average of $0.32 \pm 0.1$ ruptures per spheroid per 24-h period (Fig. 4b), with significant variations between the three lines that were analyzed $(P \leq 0.01)$. Within a given 24 -h time period, some spheroids did not rupture at all, whereas some spheroids ruptured more than once. Overall, $43 \pm 10 \%$ of spheroids in each line analyzed showed rupture events. We did not observe any significant difference in rupture frequency between low passage $(<10)$ and high passage (>10) spheroids (Fig. 4c). Interestingly, there was a trend for an increased rupture frequency in larger epithelial spheroids (Fig. 4d).

Imaging of EGFP-expressing epithelial spheroids with a combination of fluorescence confocal imaging, backscatter confocal imaging (Mollazade et al. 2012) and bright field imaging revealed that rupture events were focal and associated with the release of material with increased scattering properties - possibly mucus and cell debris-from the spheroid lumen (Fig. 5a-c'"'"; Suppl. Movie 2). To visualize loss of material from the spheroid lumen, we performed live imaging on gastric epithelial spheroids that were microinjected with 4kDa FITC-Dextran. As shown in Fig. 5d-e'"'", injected FITCDextran remained in the spheroid lumen for $>12 \mathrm{~h}$, indicating that the epithelial barrier of the spheroids was intact. Upon rupture, the FITC-Dextran completely disappeared from the spheroid lumen (Fig. 5d-e'"'"; Suppl. Movie 3). Notably, epithelial thickness was low prior to rupture events and increased immediately following a rupture event. In summary, our data show that spontaneous spheroid rupture is a common event and involves release of luminal material.

\section{Human gastric spheroids rotate within the Matrigel matrix}

Surprisingly, our live imaging analysis also revealed that, even in the absence of rupture events, spheroid interactions with the Matrigel matrix were not static. In particular, spheroids frequently rotated around an axis, with an average of $53.6 \pm 11.4 \%$ of spheroids in all cultures analyzed displaying rotational movement within the matrix (Fig. 6a-a'"'"', b; Suppl. Movie 4). This behavior was predominantly observed in smaller spheroids $(<100 \mu \mathrm{m}$ in diameter, data not shown) but showed a large variation between individual spheroid lines and individual cultures. Again, there was no significant difference between low passage $(\leq \mathrm{p} 10)$ or high passage $(>10)$ spheroids. To further investigate the dynamic interactions between the spheroids and the Matrigel, we performed backscatter light imaging (Fig. 6c-c"; Suppl. Movie 5). This backscatter light analysis revealed that spheroid epithelia form temporary, pseudopod-like basolateral projections that may enable movement of the spheroids within the Matrigel capsule.

\section{Adjacent spheroids may undergo membrane fusion}

Live imaging analysis also revealed that, in some cases, two adjacent spheroids fused to form one larger spheroid (Fig. 7). These events were rare but seen in three out of five different lines analyzed between passages 4 and 18 (Fig. 7a-a'"'"', b). To confirm that the observed events represented true luminal fusions, spheroids that had been injected with FITC-Dextran $(4 \mathrm{kDa})$ were monitored by 
Day 3

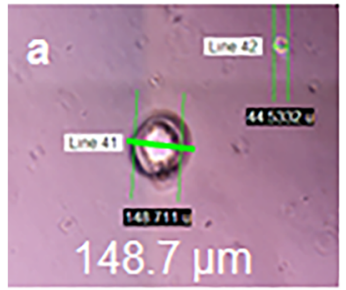

Day 5

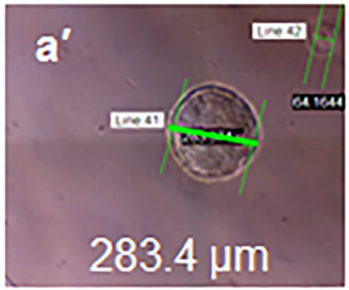

Day 7

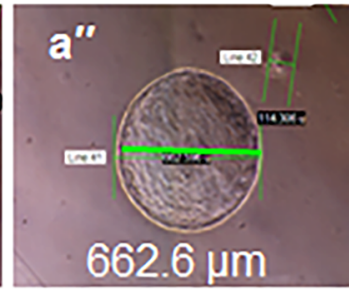

Day 10

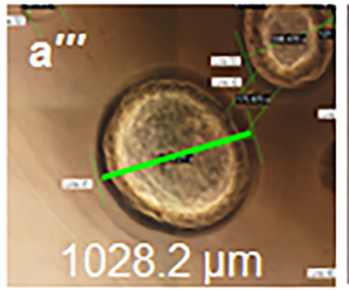

Day 12

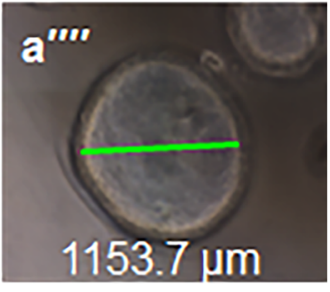

b

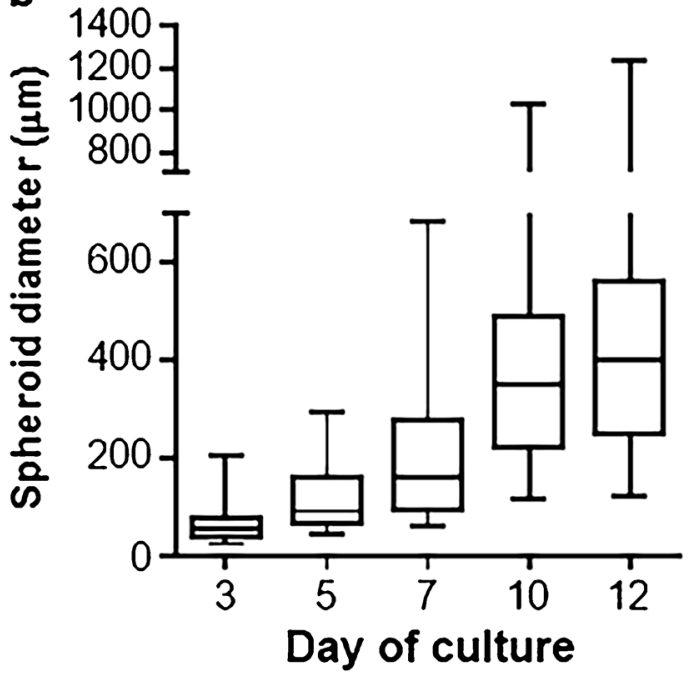

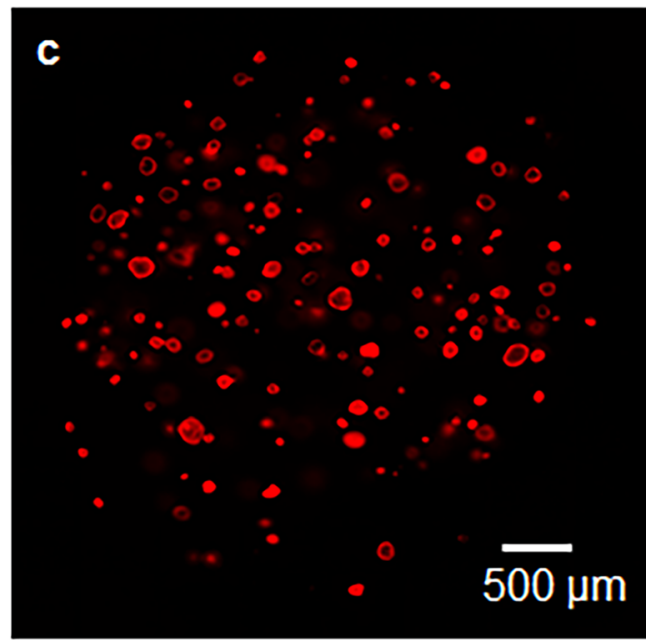

d

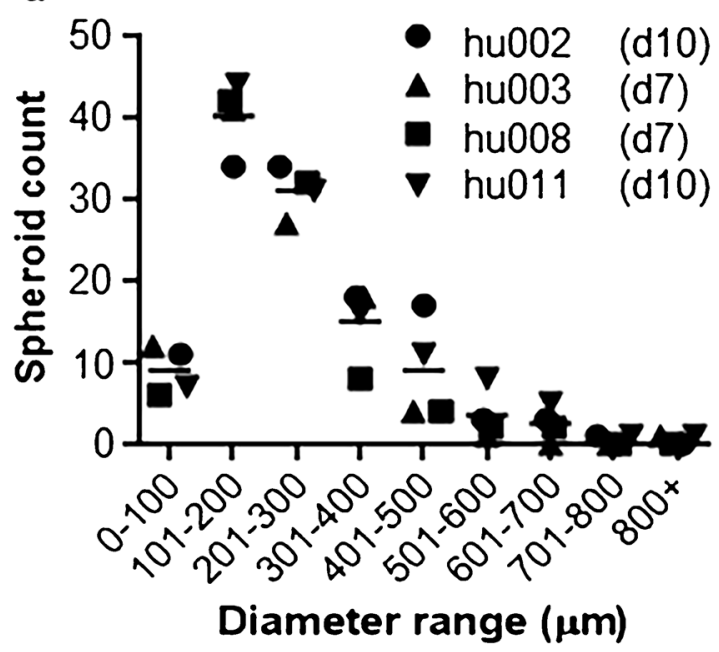

Fig. 3 Gastric epithelial spheroid growth. a- a""' Representative phase contrast images of one gastric epithelial spheroid imaged repeatedly between days 3 and 12 after plating (line hu001, p17). b Diameters of 65 randomly selected spheroids in one representative well (line hu001, p17) were measured repeatedly on days $3,5,7,10$ and 12 after plating. Box delineates 1st and 3rd quartile and median, whiskers show minimum and maximum size. c Composite image of a representative culture well containing mCherry-expressing human gastric spheroids; bar $500 \mu \mathrm{m}$. d

live confocal imaging. As shown in Fig. 7c-d"'" and Suppl. Movie 6, spheroid fusion resulted in the transfer of green fluorescent FITC-Dextran from the lumen of one injected

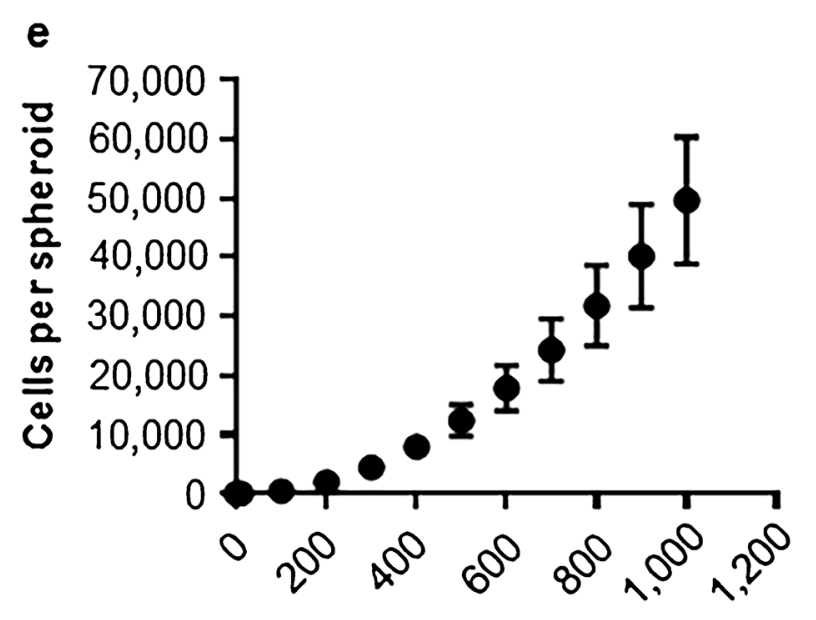

Size distribution of gastric epithelial spheroids in one representative well each from 4 different lines, imaged on days 7 or 10 after seeding (see label); graph shows mean (-) and individual values for the 4 spheroid lines. e Relationship between spheroid diameter and cell count was determined by measuring all spheroids within one well followed by disruption of the spheroids using trypsin-EDTA and hemocytometer cell counting. Averages \pm SEM calculated from 3 independent cultures are shown

spheroid to a non-injected spheroid. These observations indicate that spheroid fusions lead to the formation of a common luminal compartment. 

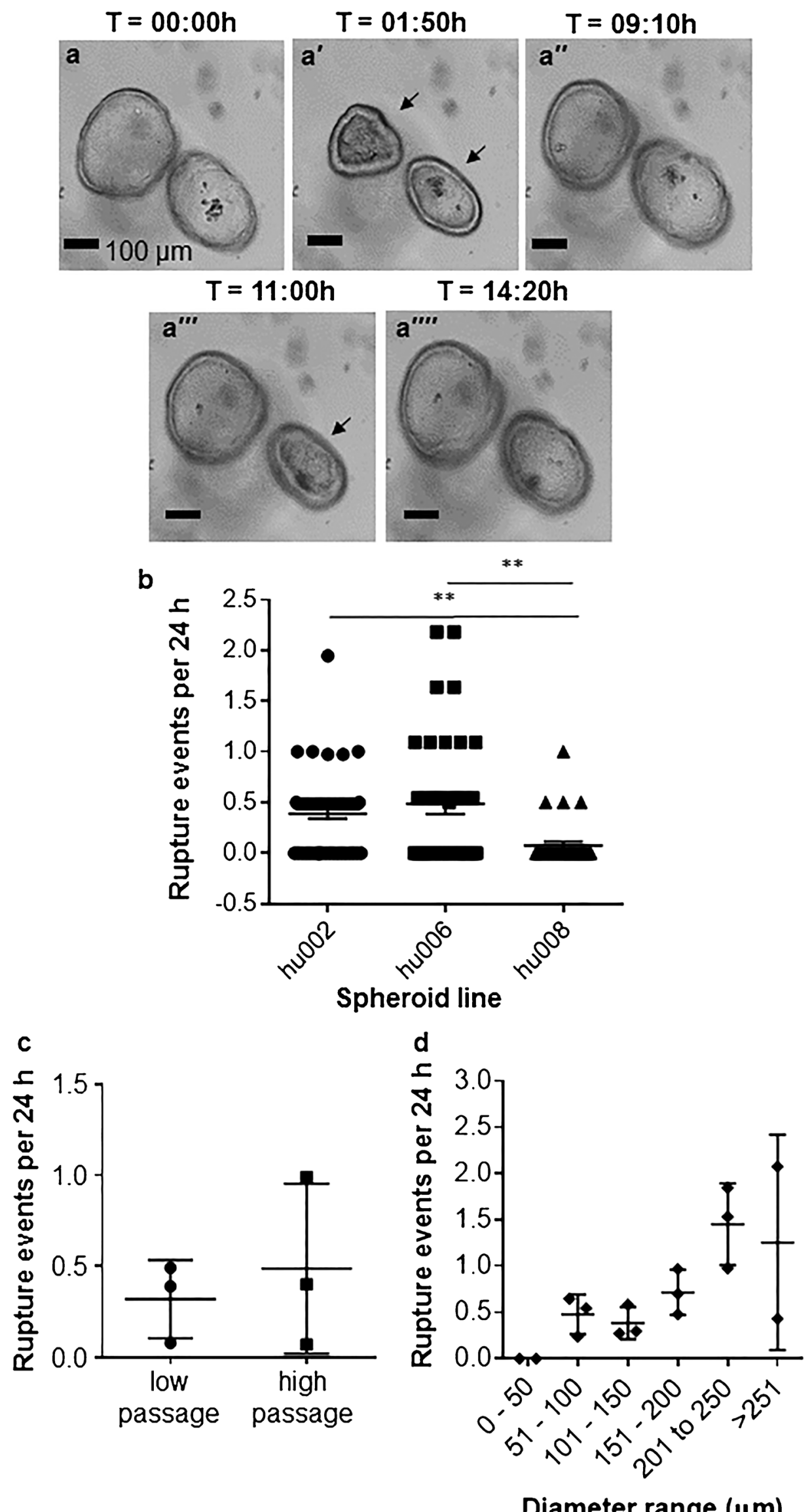

Diameter range $(\mu \mathrm{m})$ 
Fig. 4 Spontaneous spheroid rupture and healing. a-a"'"' Representative image series from a 22-h time course experiment shows epithelial spheroid expansion and rupture (indicated by arrows), followed by reforming and continued expansion over time. Phase contrast images; bar $100 \mu \mathrm{m}$. b Frequency of rupture events in 3 different gastric epithelial spheroid lines analyzed at passage $\leq 10$. Graph shows average number of rupture events per 24-h period for individual spheroids $(n=33-59)$ and mean \pm SD of each line. **Statistically significant difference at $P \leq 0.01$. c Average rupture frequency per $24 \mathrm{~h}$ in low passage number cultures $(P \leq 10$; hu002, $n=59$; hu006, $n=38$; hu008, $n=33)$ and high passage number cultures $(P>11$, hu001, $n=9$; hu004, $n=9$; hu006, $n=45$ ); individual values, mean $\pm \mathrm{SD}$; .s. not significant. d Relationship between rupture frequency and size. Spheroid lines hu001 ( $n=33$ spheroids), hu002 $(n=53)$ and hu006 $(n=31)$ were analyzed

\section{Discussion}

In this study, we used live imaging to demonstrate that human gastric epithelial spheroids - or gastrospheres (Stelzner et al. 2012) - cultured under the conditions described (see "Materials and methods") display several dynamic behaviors that may be overlooked when performing end-point analyses and that may impact experimental results. Specifically, spheroids spontaneously ruptured and sometimes fused and frequently rotated in the Matrigel matrix. Notably, there were significant differences in the behavior of distinct gastric spheroid lines and in the behavior of individual spheroid lines analyzed after a different number of passages.

Spontaneous rupture was a relatively common event, with $>40 \%$ of spheroids imaged showing rupture events. Videos included in several previous publications on murine intestinal organoids and human gastric organoids also showed organoid ruptures, although these events were not addressed directly (Mahe et al. 2013; Schlaermann et al. 2016; Schwank et al. 2013), which suggests that spontaneous ruptures are not specific to the specific culture conditions used here. In our study, we quantified rupture events and demonstrated that ruptures occurred in all gastric spheroid lines analyzed in our laboratory. We also showed that ruptures were preceded by thinning of the epithelium, suggesting that the luminal pressure of the spheroids increased over time. There was a trend for larger spheroids to rupture more frequently but the reasons for this increased rupture behavior are unclear. Since the gastric epithelium normally lines a tubular structure rather than a closed sphere, mechanisms that prevent rupture are not likely to exist. Notably, our observation that spheroids rupture on a regular basis could theoretically impact the outcome of experiments if injected microorganisms or other luminally secreted substances were to be released into the Matrigel and unexpectedly interacted with the basolateral side of the epithelium.

Gastric spheroids generally underwent additional growth following rupture, indicating efficient and rapid epithelial restitution. As previously described (Bartfeld et al. 2015; Miyoshi and Stappenbeck 2013), isolated glands spontaneously form spheres within several hours, which represents another example of epithelial healing behavior. Moreover, we observed that adjacent spheroids occasionally fused, which may also represent a healing mechanism. The ability of organoids to contribute to epithelial healing has been previously demonstrated. In a recent study by Engevik et al. (2016), gastric organoids were transplanted into the gastric submucosa of mice following chemical induction of gastric ulcers. These transplanted organoids significantly improved gastric wound healing, demonstrating that gastric organoids efficiently regenerate defective epithelia (Engevik et al. 2016). Similarly, colonic organoids improved the healing of epithelial defects in the murine colon (Yui et al. 2012). Such woundhealing behavior of gastrointestinal epithelia involves chemotactic migration of epithelial cells and epithelial flattening and lateral lamellipodia extension that lead to rapid closure of epithelial gaps independent of cell proliferation (Iizuka and Konno 2011; Silen and Ito 1985; Smith et al. 2005). In addition, the efficient reformation of spheroids after rupture and the fusion of closely adjacent spheroids was possibly enhanced by the high medium concentrations of Wnt, which promotes gastrointestinal epithelial wound healing (Miyoshi 2017).

Notably, gastrointestinal epithelial cells are highly dynamic in vivo, with a high epithelial cell turnover rate and efficient closure of gaps caused by apoptotic cell extrusion (Heath 1996; Williams et al. 2015). Gastric surface mucus cells migrate from the isthmus, where stem cells are located, to the surface mucosa within 1-3 days (Creamer et al. 1961; Karam et al. 1997; Lipkin 1965). Intestinal epithelial cells move as much as $5-10 \mu \mathrm{m} / \mathrm{h}$ from the base of the crypts towards the tips of the villi and apical junctional complexes have to be constantly re-organized to close gaps left by epithelial cells that undergo apoptosis (lizuka and Konno 2011). This constant reformation of intracellular junctions due to epithelial cell turnover may have played a role in the formation of cell-cell junctions in the observed fusions of intact spheroids.

It remains unclear whether the formation of dynamic pseudopods observed on the basolateral side of human gastric spheroids was a normal process or specific to our culture conditions. Basal pseudopodia or lamellipodia that may promote epithelial cell movement have been identified in normal intestinal epithelium but they occur at low frequencies (Heath 1996). In contrast, basal pseudopodia play a major role in epithelial carcinogenesis, where pseudopodia can contribute to invasion and matrix degradation by expanding tumors (McNiven 2013). Basal pseudopod-like processes in the small intestine also appear to be more frequent during early development (Burgess 1976) and on certain types of enteroendocrine cells, where they are thought to allow directed secretion of hormones (Bohorquez et al. 2011). In our spheroid cultures, increased basal pseudopod formation might be associated with the low differentiation stage of the cells or might have been provoked by the specific characteristics of 

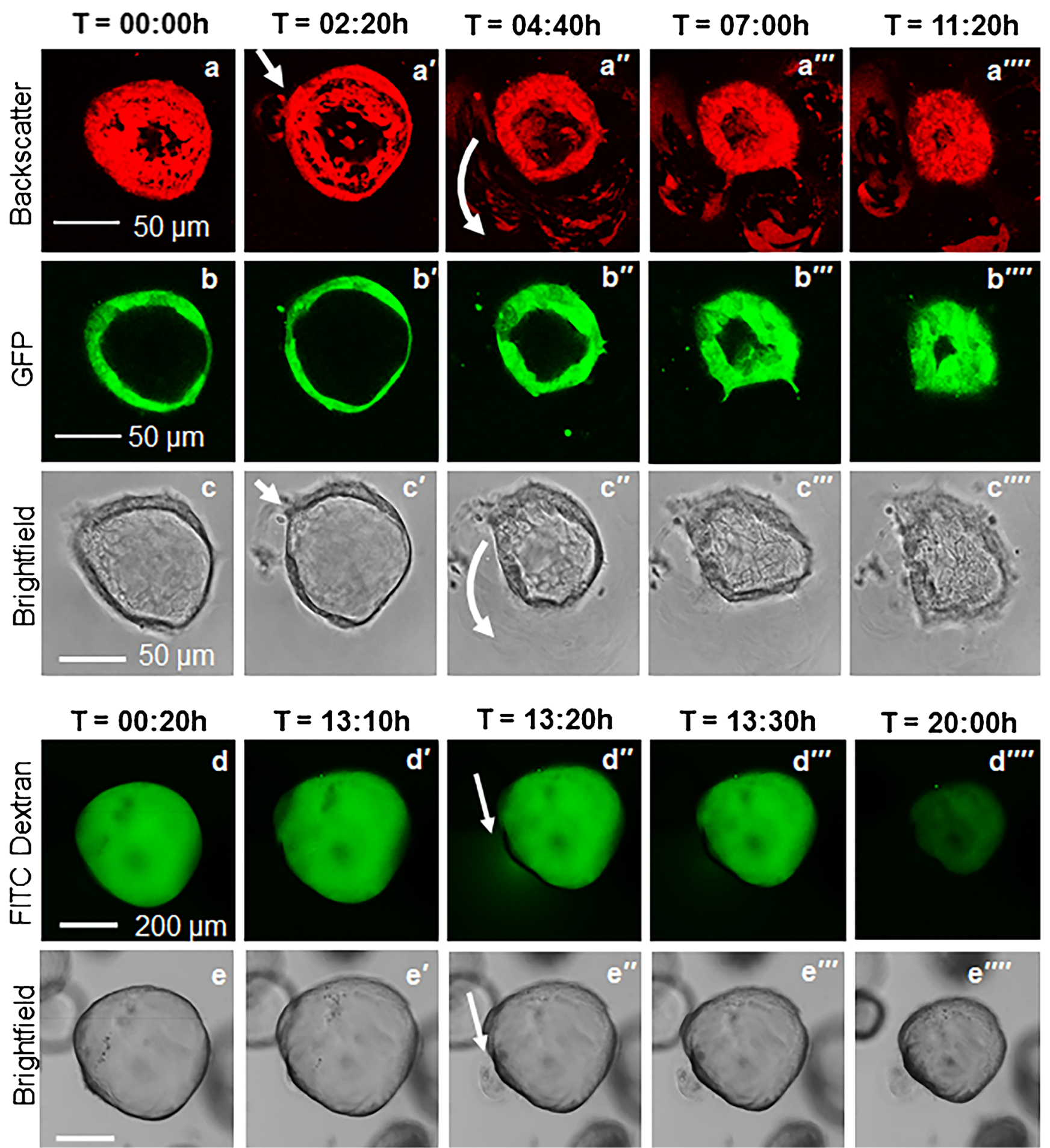

Fig. 5 Release of luminal contents from ruptured gastric epithelial spheroids. a- c'"'" Confocal and backscatter light image series from a 14-h time course analysis shows rupture, release of optically dense material $\left(\mathbf{a}-\mathbf{a}^{\prime \prime \prime \prime}\right)$ from the inside of the GFP-expressing spheroid $(\mathbf{b}-\mathbf{b}$ "'"') and thickening of the epithelial layer upon healing. $\mathbf{c}-\mathbf{c}^{\prime \prime \prime \prime}$

Brightfield images. Bar $50 \mu \mathrm{m}$. d- $\mathbf{e}^{\prime \prime \prime \prime \prime}$ Release of injected 4-kDa FITC-Dextran (d- $\left.\mathbf{d}^{\prime \prime \prime \prime}\right)$ from an mCherry-expressing gastric spheroid $\left(\mathbf{e}-\mathbf{e}^{\prime \prime \prime \prime}\right)$ upon rupture. Images show disappearance of green FITCDextran signal after rupture at 13:20 hours. Bar $200 \mu \mathrm{m}$

the Matrigel matrix, which differs from normal basement membrane and extracellular matrix in composition and structure (Benton et al. 2009). Since pseudopodia are generally associated with cellular movement, these processes may have enabled spheroid movement including the observed rotation and fusion events within the Matrigel shell.

Our detailed analysis of gastric spheroid growth under previously published culture conditions (Demitrack et al. 2017; 


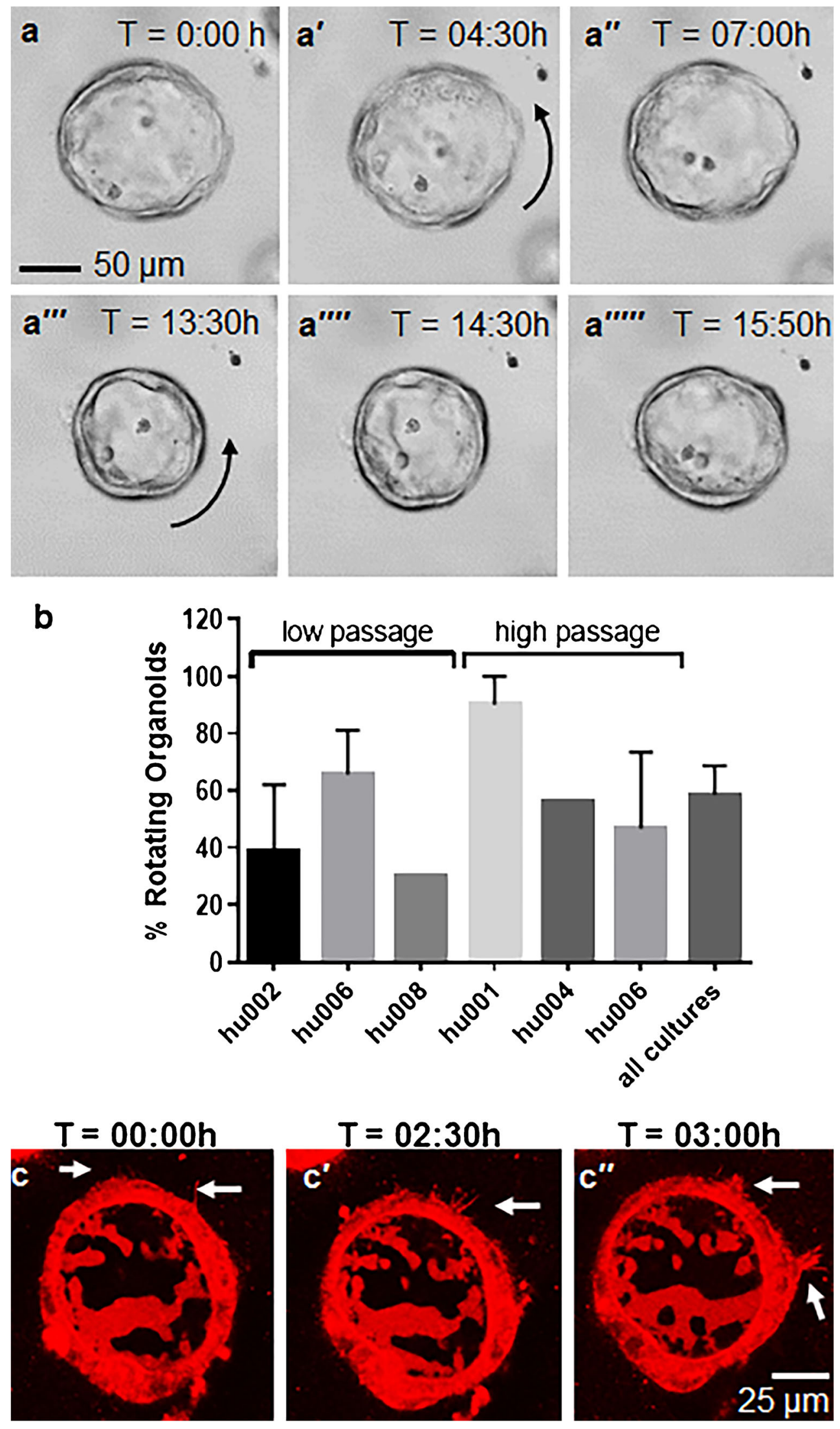


4 Fig. 6 Gastric epithelial spheroids rotate within the Matrigel. Spheroids commonly rotate around their axis within the Matrigel matrix. a- $\mathbf{a}^{\prime \prime \prime \prime \prime}$ Representative image series of a small single spheroid observed rotating counter-clockwise as indicated by the arrows over a time course of $16 \mathrm{~h}$. b Percentage of low passage (hu002, p8-10, $n=59$; hu006, p7-10, $n=38$; hu008, p4, $n=33$ ) and high passage gastric spheroids (hu001, p44-45, $n=9$; hu004, p18, $n=9$; hu006, p11-16, $n=45$ ) observed for $46 \pm 1 \mathrm{~h}$ that showed rotation. Bars mean \pm SEM of individual cultures $(n=1-3$ per line). The percentage of rotating epithelial spheroids did not differ significantly between individual lines. $\mathbf{c}-\mathbf{c}^{\prime \prime}$ Backscatter light imaging reveals basolateral formation of pseudopod-like extensions. Arrows indicate pseudopods. Bar $25 \mu \mathrm{m}$ den Hartog et al. 2016; Gifford et al. 2017; Miyoshi and Stappenbeck 2013) revealed several additional interesting properties of this model system. Thus, although some spheroids grew to a size of $>1000 \mu \mathrm{m}$ in diameter, the percentage of these large spheroids was $<0.5 \%$, while the majority of spheroids remained in the $100-300 \mu \mathrm{m}$ diameter size range after 7 10 days in culture. Also, we never observed spheroids that grew larger than $1300 \mu \mathrm{m}$. Interestingly, TEM analysis of the cultures revealed extensive formation of lateral interdigitating folds, as also observed in some gastric tissue specimens in previous studies (Necchi et al. 2009). Structurally similar
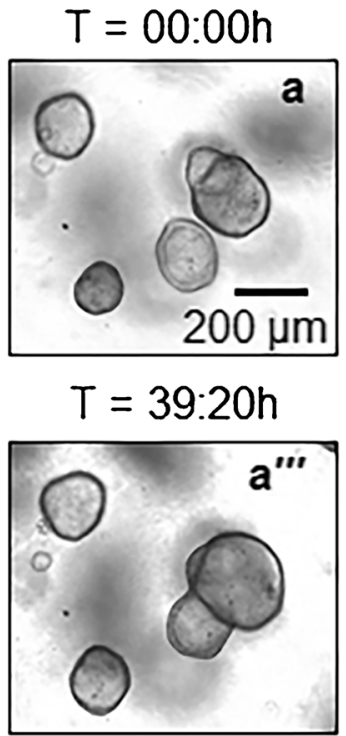
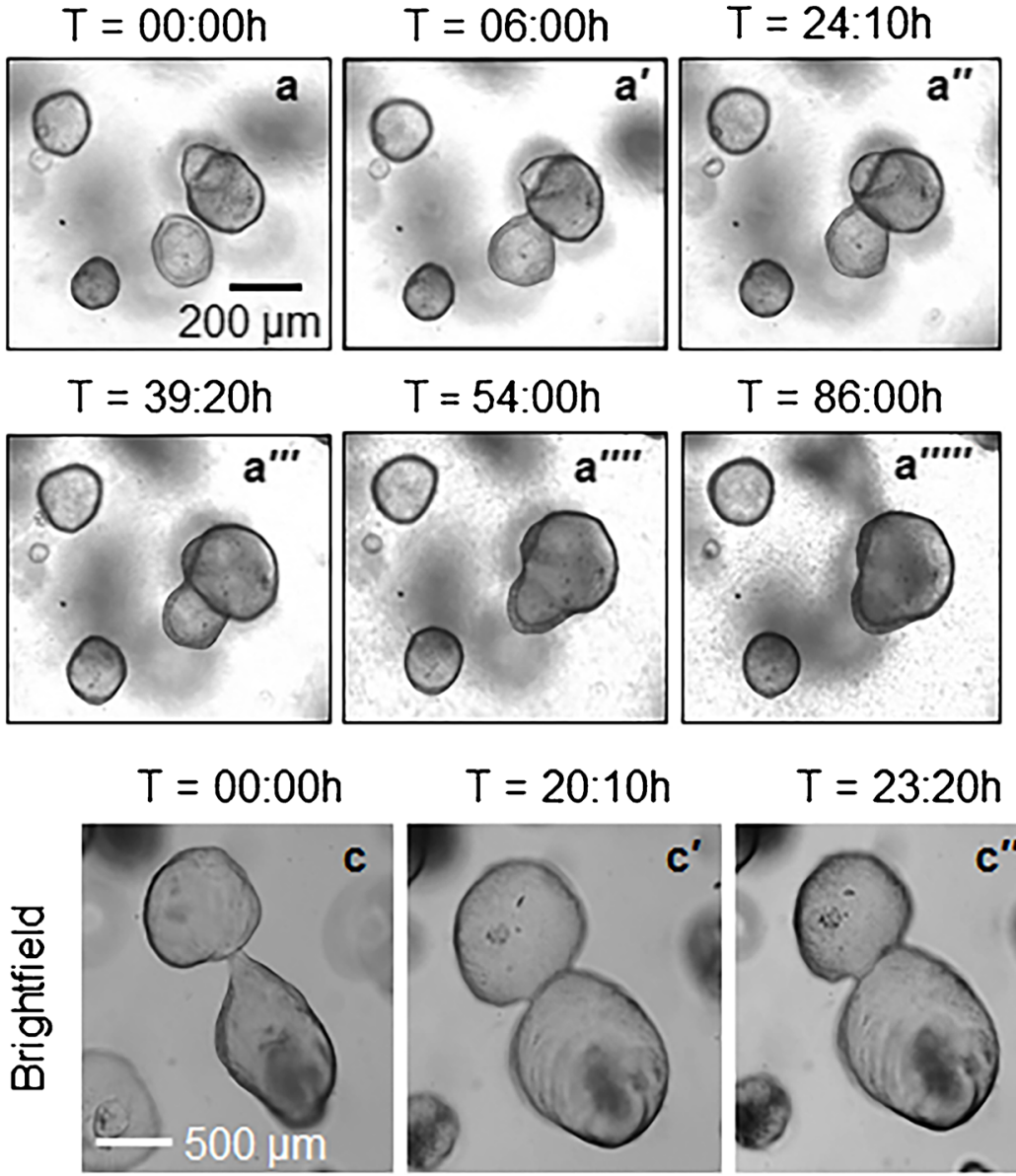

$$
T=20: 10 h
$$
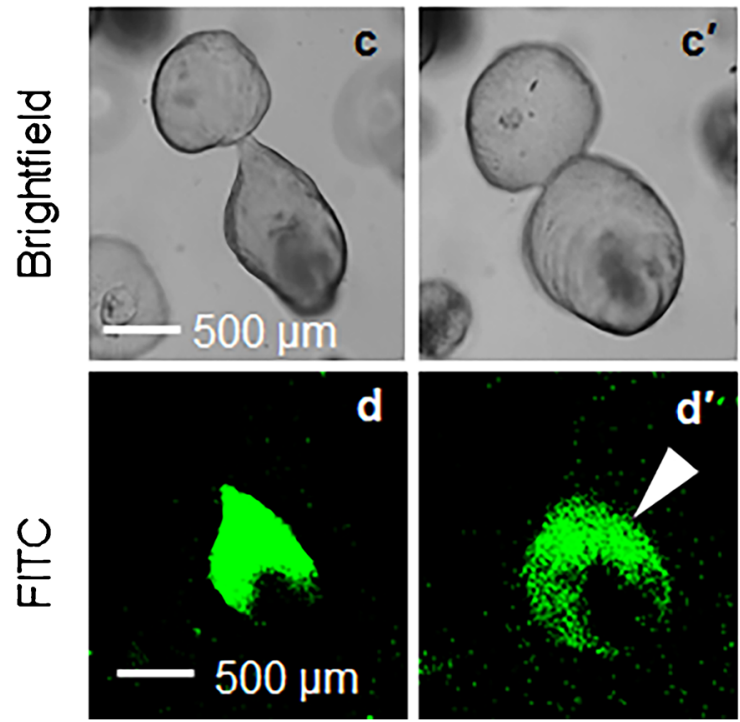

Fig. 7 Gastric epithelial spheroid fusion events. a- a'"'" Phase contrast image series of two human gastric spheroids undergoing fusion. Spheroid line hu004. Bar $200 \mu \mathrm{m}$. b Percentage of spheroids with observed fusion events in 5 different human gastric spheroid lines (hu001, p10, $n=149$; hu002, p8-10, $n=59$; hu004, p18, $n=9$; hu006, p7-16, $n=83$; and b
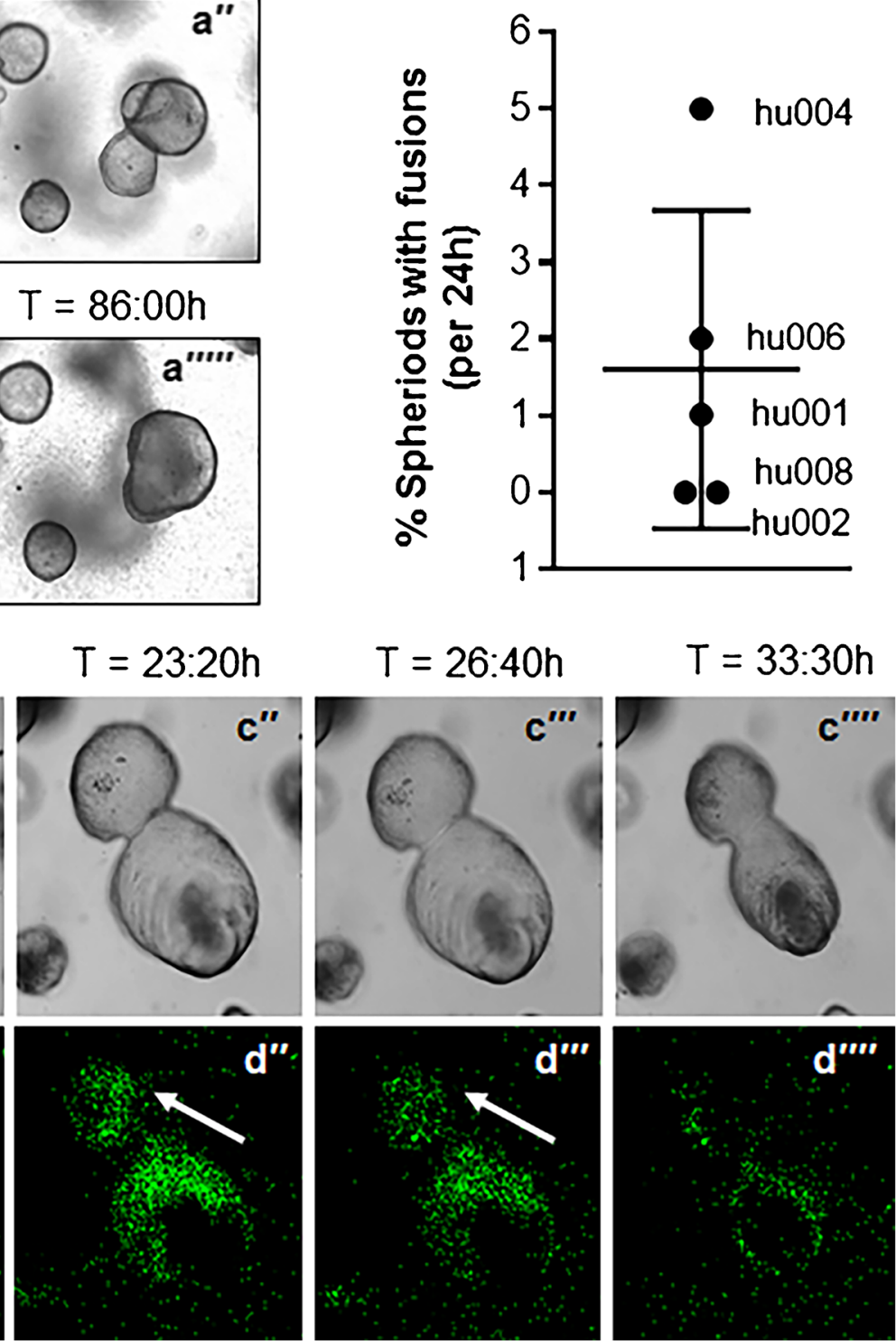

hu008, p4, $n=33$ ), normalized to a 24-h observation period. c- $\mathbf{d}^{\prime \prime \prime \prime} 4$ $\mathrm{kDa}$ FITC-Dextran injected into one gastric spheroid (arrowhead) is transferred to an adjacent spheroid upon membrane fusion (arrow). Bright field $\left(\mathbf{c}-\mathbf{c}^{\prime \prime \prime \prime}\right)$ and green fluorescent images $\left(\mathbf{d}-\mathbf{d}^{\prime \prime \prime \prime}\right)$. Spheroid line hu006. Bar $500 \mu \mathrm{m}$ 
lateral folds have been detected in the gall bladder and other epithelial tissues with increased ion transport capacity and have been implicated in contributing to water retention (Diamond and Tormey 1966; Larsen et al. 2009).

Notably, we did not alter the composition of the culture media during the experiments in order to induce gastric epithelial cell differentiation and our spheroids did not develop gland-like invaginations. Differentiation of primary gastric epithelial cell cultures has previously been achieved by withdrawal of Wnt and noggin (Sato and Clevers 2015) or Notch inhibition (Demitrack et al. 2015, 2017; VanDussen et al. 2015). Since we detected expression of genes specific for all five major epithelial cell subsets and the TEM analysis revealed structures very similar to the intracellular canaliculi that are considered typical for gastric parietal cells, we consider the epithelial cells in our cultures partially differentiated. It remains unknown whether the behaviors and growth dynamics described here similarly occur under culture conditions different from the ones used in our study. Ruptures and organoid movement in the Matrigel have been shown for a number of different epithelial and culture protocols (Mahe et al. 2013; Schlaermann et al. 2016; Schwank et al. 2013) but the frequency of these events had not previously been evaluated. Several different protocols have been used to generate and maintain gastric organoids (Bartfeld et al. 2015; Bertaux-Skeirik et al. 2015; McCracken et al. 2014; Schlaermann et al. 2016; Schumacher et al. 2015) and variations in media composition were shown to affect organoid morphology, differentiation and growth. Future studies will evaluate whether altering culture conditions or adding drugs to affect gastric secretion, e.g., omeprazole, cimetidine or naproxen, may prevent dynamic events such as ruptures that may be undesirable for certain experimental applications.

Overall, our study revealed several interesting features of three-dimensional gastric spheroids, including spontaneous ruptures, fusions and rotation events. Interestingly, human gastric epithelial spheroid lines derived from different human donors and spheroids analyzed after a different number of passages showed marked, sometimes significant, differences in many of the parameters analyzed. Consequently, for future studies using human spheroids, gastroids and other organoid culture systems, a general consensus within the scientific community on quality control parameters of organoids would be beneficial, so that data obtained in different laboratories with different cell lines can be compared.

Acknowledgements Funding for our study was provided by the National Institutes of Health grants K01 DK097144 (DB); R03 DK107960 (DB), the National Science Foundation, DMR-1455247 (JW) and the Montana University System Research Initiative 51040MUSRI2015-03 (DB). We greatly appreciate support from the National Institutes of Health IDeA Program grant GM110732, an equipment grant from the M.J. Murdock Charitable Trust and the Montana State University Agricultural Experimental Station for the Flow Cytometry
Core Facility at Montana State University. Funding for shared facilities used in this work was also provided by the NSF under award number CBET-1039785. GeneSearch, Inc. development of the GeneSearch Embryo Cradle was funded by an SBIR grant from ORIP/NIH 5R44OD012083 (PJT). We would also like to thank Dr. K. Sasse (Sasse Surgical Associates, Reno, NV) for collecting human gastric tissue samples, Dr. T. Stappenbeck (Washington University, St. Louis) for sharing the L-WRN cell line with us and Dr. Seth Walk for helpful discussions.

Author contributions D.B., B.W., L.C.S. and J.W. planned and oversaw the experiments; T.A.S., B.S., R.B. and R.A.W. performed the experiments; P.J.T. developed microinjection equipment and protocols, B.A.P. provided human gastric tissue samples; D.B., T.A.S. and R.B. analyzed the data; T.A.S. and D.B. wrote the manuscript; all authors provided critical feedback on the manuscript.

\section{Compliance with ethical standards}

Conflict of interest statement Dr. Paul Taylor has a potential conflict of interest, since he is the owner of GeneSearch, Inc., Bozeman, MT, which manufactures the EmbryoCradle microinjector that was used in this study. None of the other authors declare a conflict of interest.

\section{References}

Bartfeld S, Bayram T, van de Wetering M, Huch M, Begthel H, Kujala P, Vries R, Peters PJ, Clevers H (2015) In vitro expansion of human gastric epithelial stem cells and their responses to bacterial infection. Gastroenterology 148:126-136

Benton G, George J, Kleinman HK, Arnaoutova IP (2009) Advancing science and technology via 3D culture on basement membrane matrix. J Cell Physiol 221:18-25

Bertaux-Skeirik N, Feng R, Schumacher MA, Li J, Mahe MM, Engevik AC, Javier JE, Peek RM Jr, Ottemann K, Orian-Rousseau V, Boivin GP, Helmrath MA, Zavros Y (2015) CD44 plays a functional role in helicobacter pylori-induced epithelial cell proliferation. PLoS Pathog 11:e1004663

Bimczok D, Smythies LE, Waites KB, Grams JM, Stahl RD, Mannon PJ, Peter S, Wilcox CM, Harris PR, Das S, Ernst PB, Smith PD (2013) Helicobacter pylori infection inhibits phagocyte clearance of apoptotic gastric epithelial cells. J Immunol 190(12):6626-6634

Bimczok D, Kao JY, Zhang M, Cochrun S, Mannon P, Peter S, Wilcox CM, Mönkemüller KE, Harris PR, Grams JM, Stahl RD, Smith PD, Smythies LE (2014) Human gastric epithelial cells contribute to gastric immune regulation by providing retinoic acid to dendritic cells. Mucosal Immunol 8(3):533-544

Bohorquez DV, Chandra R, Samsa LA, Vigna SR, Liddle RA (2011) Characterization of basal pseudopod-like processes in ileal and colonic PYY cells. J Mol Histol 42:3-13

Bradford EM, Ryu SH, Singh AP, Lee G, Goretsky T, Sinh P, Williams DB, Cloud AL, Gounaris E, Patel V, Lamping OF, Lynch EB, Moyer MP, De Plaen IG, Shealy DJ, Yang GY, Barrett TA (2017) Epithelial TNF receptor signaling promotes mucosal repair in inflammatory bowel disease. J Immunol 199:1886-1897

Brumfield SK, Ortmann AC, Ruigrok V, Suci P, Douglas T, Young MJ (2009) Particle assembly and ultrastructural features associated with replication of the lytic archaeal virus sulfolobus turreted icosahedral virus. J Virol 83:5964-5970

Burgess DR (1976) Structure of the epithelial - mesenchymal interface during early morphogenesis of the chick duodenum. Tissue Cell 8: $147-158$ 
Corpron RE (1966) The ultrastructure of the gastric mucosa in normal and hypophysectomized rats. Am J Anat 118:53-90

Creamer B, Shorter RG, Bamforth J (1961) The turnover and shedding of epithelial cells. I. The turnover in the gastro-intestinal tract. Gut 2: 110-118

Dedhia PH, Bertaux-Skeirik N, Zavros Y, Spence JR (2016) Organoid models of human gastrointestinal development and disease. Gastroenterology 150:1098-1112

Dekkers JF, Wiegerinck CL, de Jonge HR, Bronsveld I, Janssens HM, de Winter-de Groot KM, Brandsma AM, de Jong NW, Bijvelds MJ, Scholte BJ, Nieuwenhuis EE, van den Brink S, Clevers H, van der Ent CK, Middendorp S, Beekman JM (2013) A functional CFTR assay using primary cystic fibrosis intestinal organoids. Nat Med 19: 939-945

Demitrack ES, Gifford GB, Keeley TM, Carulli AJ, VanDussen KL, Thomas D, Giordano TJ, Liu Z, Kopan R, Samuelson LC (2015) Notch signaling regulates gastric antral LGR5 stem cell function. EMBO J 34:2522-2536

Demitrack ES, Gifford GB, Keeley TM, Horita N, Todisco A, Turgeon DK, Siebel CW, Samuelson LC (2017) NOTCH1 and NOTCH2 regulate epithelial cell proliferation in mouse and human gastric corpus. Am J Physiol Gastrointest Liver Physiol 312:G133-G144

Diamond JM, Tormey JM (1966) Role of long extracellular channels in fluid transport across epithelia. Nature 210:817-820

Engevik AC, Feng R, Choi E, White S, Bertaux-Skeirik N, Li J, Mahe MM, Aihara E, Yang L, DiPasquale B, Oh S, Engevik KA, Giraud AS, Montrose MH, Medvedovic M, Helmrath MA, Goldenring JR, Zavros Y (2016) The development of spasmolytic polypeptide/ TFF2-expressing metaplasia (SPEM) during gastric repair is absent in the aged stomach. Cell Mol Gastroenterol Hepatol 2:605-624

Gifford GB, Demitrack ES, Keeley TM, Tam A, La Cunza N, Dedhia PH, Spence JR, Simeone DM, Saotome I, Louvi A, Siebel CW, Samuelson LC (2017) Notch1 and Notch2 receptors regulate mouse and human gastric antral epithelial cell homoeostasis. Gut 66:10011011

den Hartog G, Chattopadhyay R, Ablack A, Hall EH, Butcher LD, Bhattacharyya A, Eckmann L, Harris PR, Das S, Ernst PB, Crowe SE (2016) Regulation of Rac1 and reactive oxygen species production in response to infection of gastrointestinal epithelia. PLoS Pathog 12:e1005382

Heath JP (1996) Epithelial cell migration in the intestine. Cell Biol Int 20: 139-146

Howitt MR, Lavoie S, Michaud M, Blum AM, Tran SV, Weinstock JV, Gallini CA, Redding K, Margolskee RF, Osborne LC, Artis D, Garrett WS (2016) Tuft cells, taste-chemosensory cells, orchestrate parasite type 2 immunity in the gut. Science 351:1329-1333

Hynds RE, Giangreco A (2013) Concise review: the relevance of human stem cell-derived organoid models for epithelial translational medicine. Stem Cells 31:417-422

Iizuka M, Konno S (2011) Wound healing of intestinal epithelial cells. World J Gastroenterol 17:2161-2171

Karam SM, Li Q, Gordon JI (1997) Gastric epithelial morphogenesis in normal and transgenic mice. Am J Phys 272:G1209-G1220

Larsen EH, Willumsen NJ, Mobjerg N, Sorensen JN (2009) The lateral intercellular space as osmotic coupling compartment in isotonic transport. Acta Physiol (Oxford) 195:171-186

Leushacke M, Barker N (2014) Ex vivo culture of the intestinal epithelium: strategies and applications. Gut 63:1345-1354

Lipkin M (1965) Cell replication in the gastrointestinal tract of man. Gastroenterology 48:616-624

Mahe MM, Aihara E, Schumacher MA, Zavros Y, Montrose MH, Helmrath MA, Sato T, Shroyer NF (2013) Establishment of gastrointestinal epithelial organoids. Curr Protoc Mouse Biol 3:217-240

McCracken KW, Cata EM, Crawford CM, Sinagoga KL, Schumacher M, Rockich BE, Tsai YH, Mayhew CN, Spence JR, Zavros Y, Wells JM
(2014) Modelling human development and disease in pluripotent stem-cell-derived gastric organoids. Nature 516:400-404

McNiven MA (2013) Breaking away: matrix remodeling from the leading edge. Trends Cell Biol 23:16-21

Miyoshi H (2017) Wnt-expressing cells in the intestines: guides for tissue remodeling. J Biochem 161:19-25

Miyoshi H, Stappenbeck TS (2013) In vitro expansion and genetic modification of gastrointestinal stem cells in spheroid culture. Nat Protoc 8:2471-2482

Miyoshi H, Ajima R, Luo CT, Yamaguchi TP, Stappenbeck TS (2012) Wnt5a potentiates TGF-beta signaling to promote colonic crypt regeneration after tissue injury. Science 338:108-113

Mollazade K, Omid M, Tab FA, Mohtasebi SS (2012) Principles and applications of light backscattering imaging in quality evaluation of agro-food products: a review. Food Bioprocess Technol 5: $1465-1485$

Necchi V, Manca R, Ricci V, Solcia E (2009) Evidence for transepithelial dendritic cells in human H. Pylori active gastritis. Helicobacter 14: 208-222

Ootani A, Li X, Sangiorgi E, Ho QT, Ueno H, Toda S, Sugihara H, Fujimoto K, Weissman IL, Capecchi MR, Kuo CJ (2009) Sustained in vitro intestinal epithelial culture within a Wntdependent stem cell niche. Nat Med 15:701-706

Pechhold K, Pohl T, Kabelitz D (1994) Rapid quantification of lymphocyte subsets in heterogeneous cell populations by flow cytometry. Cytometry 16:152-159

Powell RH, Behnke MS (2017) WRN conditioned media is sufficient for in vitro propagation of intestinal organoids from large farm and small companion animals. Biol Open 6:698-705

Riehl TE, Santhanam S, Foster L, Ciorba M, Stenson WF (2015) CD44 and TLR4 mediate hyaluronic acid regulation of Lgr5+ stem cell proliferation, crypt fission, and intestinal growth in postnatal and adult mice. Am J Physiol Gastrointest Liver Physiol 309:G874G887

Rohrer GV, Scott JR, Joel W, Wolf S (1965) The fine structure of human gastric parietal cells. Am J Dig Dis 10:13-21

Sancak Y, Peterson TR, Shaul YD, Lindquist RA, Thoreen CC, Bar-Peled L, Sabatini DM (2008) The rag GTPases bind raptor and mediate amino acid signaling to mTORC1. Science 320:1496-1501

Sato T, Clevers H (2015) SnapShot: growing organoids from stem cells. Cell 161:1700-1700 e1701

Sato T, Vries RG, Snippert HJ, van de Wetering M, Barker N, Stange DE, van Es JH, Abo A, Kujala P, Peters PJ, Clevers H (2009) Single Lgr5 stem cells build crypt-villus structures in vitro without a mesenchymal niche. Nature 459:262-265

Schlaermann P, Toelle B, Berger H, Schmidt SC, Glanemann M, Ordemann J, Bartfeld S, Mollenkopf HJ, Meyer TF (2016) A novel human gastric primary cell culture system for modelling helicobacter pylori infection in vitro. Gut 65:202-213

Schumacher MA, Aihara E, Feng R, Engevik A, Shroyer NF, Ottemann KM, Worrell RT, Montrose MH, Shivdasani RA, Zavros Y (2015) The use of murine-derived fundic organoids in studies of gastric physiology. J Physiol 593:1809-1827

Schwank G, Andersson-Rolf A, Koo BK, Sasaki N, Clevers H (2013) Generation of BAC transgenic epithelial organoids. PLoS ONE 8: e76871

Silen W, Ito S (1985) Mechanisms for rapid re-epithelialization of the gastric mucosal surface. Annu Rev Physiol 47:217-229

Smith JM, Johanesen PA, Wendt MK, Binion DG, Dwinell MB (2005) CXCL12 activation of CXCR4 regulates mucosal host defense through stimulation of epithelial cell migration and promotion of intestinal barrier integrity. Am J Physiol Gastrointest Liver Physiol 288:G316-G326

Stelzner M, Helmrath M, Dunn JC, Henning SJ, Houchen CW, Kuo C, Lynch J, Li L, Magness ST, Martin MG, Wong MH, Yu J, Consortium NIHISC (2012) A nomenclature for intestinal in vitro 
cultures. Am J Physiol Gastrointest Liver Physiol 302:G1359G1363

Stewart SA, Dykxhoorn DM, Palliser D, Mizuno H, Yu EY, An DS, Sabatini DM, Chen IS, Hahn WC, Sharp PA, Weinberg RA, Novina CD (2003) Lentivirus-delivered stable gene silencing by RNAi in primary cells. RNA 9:493-501

VanDussen KL, Marinshaw JM, Shaikh N, Miyoshi H, Moon C, Tarr PI, Ciorba MA, Stappenbeck TS (2015) Development of an enhanced human gastrointestinal epithelial culture system to facilitate patientbased assays. Gut 64:911-920

van de Wetering M, Oosterwegel M, Dooijes D, Clevers H (1991) Identification and cloning of TCF-1, a T lymphocyte-specific transcription factor containing a sequence-specific HMG box. EMBO J 10:123-132

Williams JM, Duckworth CA, Burkitt MD, Watson AJ, Campbell BJ, Pritchard DM (2015) Epithelial cell shedding and barrier function: a matter of life and death at the small intestinal villus tip. Vet Pathol $52: 445-455$

Yui S, Nakamura T, Sato T, Nemoto Y, Mizutani T, Zheng X, Ichinose S, Nagaishi T, Okamoto R, Tsuchiya K, Clevers H, Watanabe M (2012) Functional engraftment of colon epithelium expanded in vitro from a single adult Lgr5(+) stem cell. Nat Med 18:618-623

Zeitoun P, Lambling A (1967) Ultrastructure of the gastric mucosa in human hemochromatosis. Scand J Gastroenterol 2:222-234 